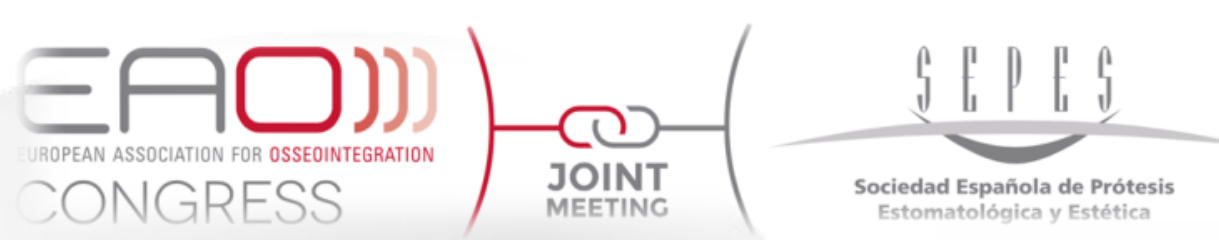

\title{
TÉCNICA DE PREPARACIÓN ORIENTADA BIOLÓGICAMENTE (BOPT) VS. LAS PREPARACIONES PROTÉSICAS CONVENCIONALES CON RESPECTO A LA SALUD PERIODONTAL
}

Canaro Borría M, Tur Colomar L, López López J, Arranz Obispo C, Ochoa García P, Jané Salas E

\section{INTRODUCCIÓN}

- Entre las complicaciones más frecuentes de las prótesis fijas sobre dientes naturales $\rightarrow$ insatisfacción estética por la migración apical del margen gingival.

- Tradicionalmente, las preparaciones para restauraciones protésicas fijas se han hecho de forma horizontal, con un margen definido ; y vertical, sin margen delimitado.

- Preparación protésica orientada biológicamente (BOPT) intenta superar problemas estéticos y funcionales de las técnicas antiguas

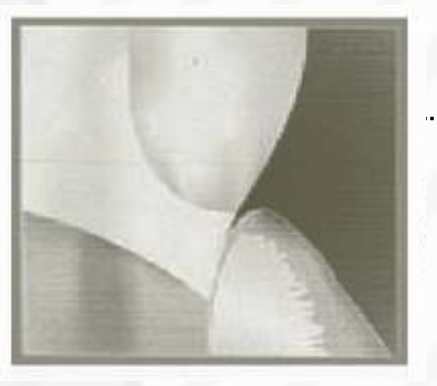

OBJETIVOS

- Explicar la técnica de preparación orientada biológicamente

- Comparar la respuesta de los tejidos periodontales en función de las distintas preparaciones de márgenes en prótesis fijas sobre dientes naturales
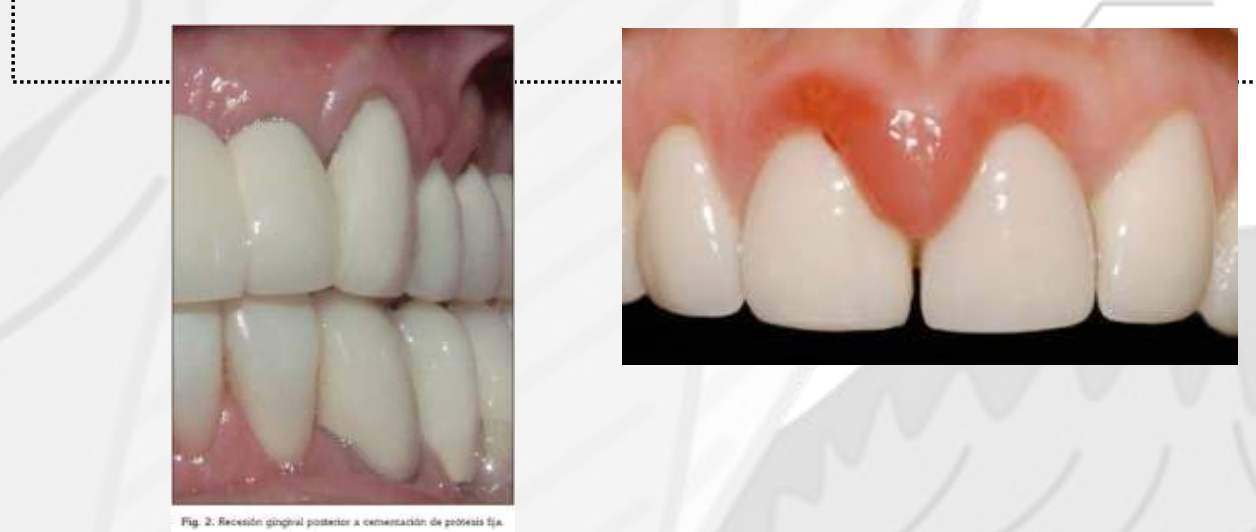

RESULTADOS

- 43 artículos

- guardados en PDF para conservar su originalidad.

\section{DISCUSIÓN}

TÉCNICA BOPT = Invasión controlada del sulcus + Estabilización del coágulo
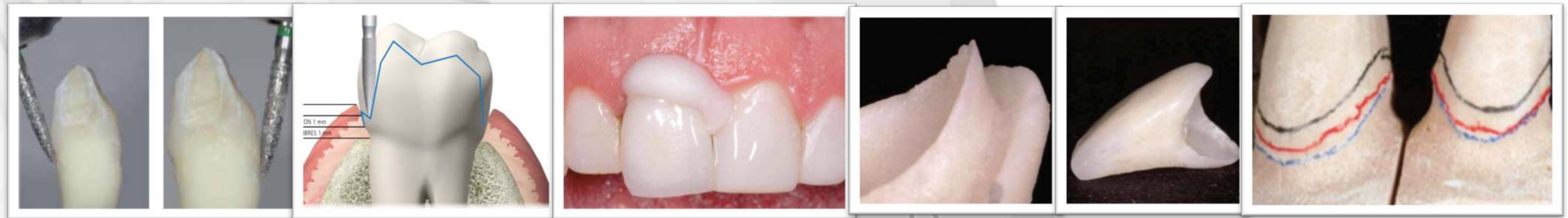

\section{TÉCNICAS CONVENCIONALES}

- Margen de terminación definido: chánfer y hombro son los más comunes

- Según la literatura $\rightarrow$ Acabado supragingival $\rightarrow$ Más beneficioso y predecible en cuanto a salud periodontal

- La invasión del espacio biologico $\rightarrow$ Factor más importante de destrucción periodontal

\section{CONCLUSIÓN}

La BOPT será exitosa sólo en manos de un operador entrenado, con material adecuado y pacientes periodontalmente sanos

$\checkmark$ Acabado intracrevicular $\rightarrow$ Pronóstico dudoso en la literatura $\rightarrow$ Lo más recomendable es una técnica convencional

supragingival

\section{BIBLIOGRAFÍA}

